\title{
Evaluation of Pregnancy Outcomes in Women with Hypertension Disorders of Pregnancy
}

KALSOOM ESSA BHATTANI ${ }^{1}$, SHUMAILA KHAWAJA KHAIL ${ }^{2}$, KASHIF ALI SAMIN ${ }^{3}$, ZUBAIDA KHANUM WAZIR ${ }^{4}$, MOBASHARA GHULAM MUHAMMAD ${ }^{5}$, RUBINA BABAR ${ }^{6}$

${ }^{1}$ Senior Registrar, Obstetrics \& Gynaecology Mufti Mehmood Memorial Teaching Hospital (MMMTH), Dera Ismail Khan.

${ }^{2}$ Specialist Registrar, Gyne Unit A MTI Lady Reading Hospital, Peshawar

${ }^{3}$ Assistant Professor Family Medicine Khyber Medical University, Peshawar

${ }^{4}$ Associate Professor Gynae/Obstetrics, Bannu Medical College, Bannu

${ }^{5}$ Senior Registrar Obstetrics \& Gynaecology Mohtarma Benazir Bhutto Shaheed Medical College, Mirpur AJK

${ }^{6}$ Senior Medical Officer, Obstetrics \& Gynaecology Mufti Mehmood Memorial Teaching Hospital (MMMTH), Dera Ismail Khan

Corresponding author: Kashif Ali Samin, Email: Kashif@kmu.edu.pk, Cell: +923009590555

\begin{abstract}
Background and Aim: Globally, hypertension disorder is the most common disorder in pregnancy. It complicates $6-10 \%$ of pregnancies with a major contribution to the worldwide maternal mortality rate. The aim of the current study was to evaluate the pregnancy outcomes in women with Hypertension disorders.

Materials and Methods: This cross-sectional study was carried out on women with hypertension disorders enrolled in the department of Gynecology, Mardan Women Hospital, Sheikh Maltoon Town, Mardan and Family Health Centre, Peshawar from March 2021 to August 2021. Demographic details such as age, gestational age, parity, intrapartum, early postpartum complications such as perinatal outcomes and mode of delivery, and antepartum were recorded from each individual. Chisquare test was used for comparing the composite adverse outcomes such as preterm birth, postpartum hemorrhage, abrupt placenta, and mortality rate. SPSS version 20 was used for data analysis.

Results: Of the total 2357 pregnant women, about $146(6.2 \%)$ women had hypertensive disorders of pregnancy. The mean age of 146 pregnant women was $29.45 \pm 4.67$ years with an age range from 17 to 43 years. About $37(25.3 \%)$ women had no perinatal and maternal complications. Out of 109 pregnant women, the prevalence of eclampsia, preeclampsia, and pregnancyinduced hypertension were 8 (7.3\%), $44(40.4 \%)$, and $57(52.3 \%)$ respectively. Based on gestational age, preterm (24-36 weeks) and term (>37 weeks) were $35(32.1 \%)$ and $74(67.9 \%)$ respectively. Other maternal complications were Abruption Placentae, Postpartum hemorrhage (PPH), Renal Failure., Pulmonary Edema, Disseminated intravascular coagulation (DIC), and Maternal Death.

Conclusion: Our study found hypertension disorders as a significant medical disorder in pregnant women. However, neonatal outcomes and pregnancy outcomes were significantly smooth in more than $50 \%$ of pregnant women.

Keywords: Hypertensive disorders of pregnancy, Pre-eclampsia, Eclampsia.
\end{abstract}

\section{INTRODUCTION}

Globally, hypertension disorder is the most common disorder in pregnancy. It complicates $6-10 \%$ of pregnancies with a major contribution to the worldwide maternal mortality rate [1]. Chronic hypertension, eclampsia, gestational hypertension, superimposed chronic hypertension, and preeclampsia is the different categories of hypertension disorders of pregnancy [2]. The mild to severe range of laboratory and clinical presentation induced by potential hypertension disorders of pregnancy causing menacing conditions for life. Though previous studies associated hypertension disorders for pregnancy with the risk of adverse outcomes on hypertension disorders of pregnancy-specific types [3]. Preeclampsia is a severe hypertension disorder of pregnancy that accounts for $9 \%$ to $26 \%$ of the mortality rate worldwide [4]. Defective placentation of preeclampsia with pathophysiological features was associated with immune imbalance, increased vascular resistance, activation of coagulation, aggregation of enhanced platelet, and endothelial dysfunction $[5,6]$. The difference of early-onset $(<34$ weeks) severity and etiology from late one have ( $>34$ weeks) has been investigated by many researchers [7, 8].Others compared the early and late-onset preeclampsia in pregnancy outcomes[9]; however, few reported severe preeclampsia such as elevated liver enzymes, Hemolysis, and low platelet count (HELLP) syndrome with pregnancy outcomes [10].

In Pakistan, two studies investigated the frequency of hypertension disorders of pregnancy and found $15 \%$ and $5.34 \%$ prevalence respectively $[11,12]$. The relatively benign conditions of $\mathrm{PIH}$ are gestational and chronic hypertension, but severe conditions comprise eclampsia and preeclampsia. Pre-eclampsia is characterized by maternal vascular dysfunction and placental, causing serious fetal and maternal complications such as severe hypertension, hemorrhage (abruption placenta and postpartum), seizures (eclampsia), kidneys and liver infections, stroke, stillbirth, and intrauterine fetal growth retardation, Regarding maternal mortality, hypertensive disorders of pregnancy account for $18 \%$ of all maternal deaths worldwide [13]. Various studies focused on specific types of preeclampsia and outcomes which limited their investigation. Another study reported that after hemorrhage eclampsia is another common cause for maternal mortality. In developing countries, about $98 \%$ of mortality is caused by eclampsia [14]. About $9 \%$ of preterm births are caused by hypertension disorders of pregnancy [15]. The majority of preterm babies are delivered with maternal severe eclampsia and preeclampsia. A number of studies investigated the neonatal and maternal complications associated with hypertension disorders of pregnancy. Considering the lack of study and literature gap, the present study was carried out to assess the frequency of hypertension disorders of pregnancy.

\section{MATERIALS AND METHODS}

This cross-sectional study was carried out on women with hypertension disorders enrolled in the department of Gynecology, Mardan Women Hospital, Sheikh Maltoon Town, Mardan and Family Health Centre, Peshawar from March 2021 to August 2021. Demographic details such as age, gestational age, parity, intrapartum, early postpartum complications such as perinatal outcomes and mode of delivery, and antepartum were recorded from each individual. Chi-square test was used for comparing the composite adverse outcomes such as preterm birth, postpartum hemorrhage, abrupt placenta, and mortality rate. Pregnancyinduced hypertension was standardized as hypertension after a gestational age of 20 weeks with $140 \mathrm{mmHg}$ of systolic blood pressure and $90 \mathrm{mmHg}$ diastolic pressure measured on two different occasions without proteinuria and 4 hours apart from one another. Severe hypertensive disorders with preeclampsia and eclampsia were at $140 \mathrm{mmHg}$ systolic and $90 \mathrm{mmHg}$ of diastolic pressure and $300 \mathrm{mg} / 24$ hours proteinuria. Severe preeclampsia was at 160/110 elevated blood pressure with $2 \mathrm{gm} / \mathrm{dl}$ while without any other cause in preeclampsia was referred to eclampsia. 
Acute renal failure (urine $\mathrm{o} / \mathrm{p}<25 \mathrm{~mL} /$ hour), cerebrovascular accident or stroke, pulmonary edema, adult intensive care unit admission, liver failure, delivery complications such as postpartum hemorrhage, placental abruption, and retained placenta, maternal mortality, coagulopathy, and hospital stay duration were the evaluated maternal complications. SPSS version 20 was used for data analysis. Informed consent and ethical approval were taken from each individual and ethical committee of the respective institute. Data like demographic details, laboratory and clinical findings, neonate outcomes, and each patient's medical record were noted on specially designed proforma.

\section{RESULTS}

Of the total 2357 pregnant women, about 146 (6.2\%) women had hypertensive disorders of pregnancy. The mean age of 146 pregnant women was $29.45 \pm 4.67$ years with an age range from 17 to 43 years. About $37(25.3 \%)$ women had no perinatal and maternal complications. Based on gestational age, preterm (24-36 weeks) and term (>37 weeks) were $35(32.1 \%)$ and $74(67.9 \%)$ respectively. Demographic details are shown in Table -1 . Other maternal complications were Abruption Placentae, Postpartum hemorrhage (PPH), Renal Failure., Pulmonary Edema, Disseminated intravascular coagulation (DIC), and Maternal Death. Figure-1 demonstrates the age wise distribution of 109 women of hypertensive disorders of pregnancy. Out of 109 pregnant women, the prevalence of eclampsia, preeclampsia, and pregnancyinduced hypertension were 8 (7.3\%), 44 (40.4\%), and 57 (52.3\%) respectively as shown in Table/Figure-2.

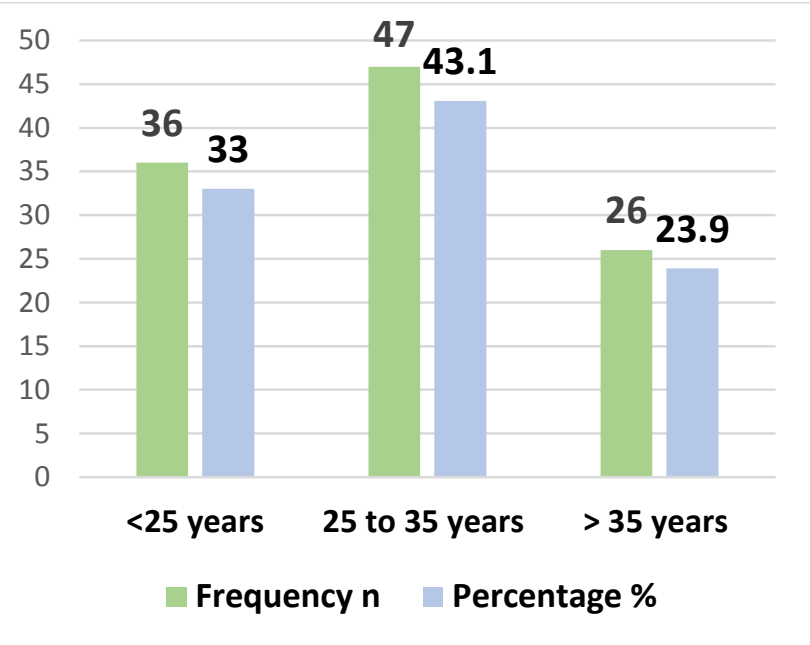

Figure-1. Age wise distribution of 109 pregnant women

Table-1. Demographic details of 109 pregnant women with HDP

Table-1. Demographic details of 109 pregnant women with HDP
\begin{tabular}{|l|l|l|}
\hline Parameters & Frequency $\mathrm{n}$ & Percentage $\%$ \\
\hline Gestational Age (Weeks) & & \\
\hline Preterm (24-36 weeks) & 35 & 32.1 \\
\hline Term (>37 weeks) & 74 & 67.9 \\
\hline Parity & & \\
\hline Primigravida & 31 & 28.4 \\
\hline Para 1- 4 & 35 & 32.1 \\
\hline Para $>5$ & 43 & 39.5 \\
\hline
\end{tabular}

Table-2. Frequency of hypertensive disorders among 109 pregnant women

\begin{tabular}{|l|l|l|}
\hline Hypertensive Disorders & Frequency n & Percentage \% \\
\hline Eclampsia & 8 & 7.3 \\
\hline Preeclampsia & 44 & 40.4 \\
\hline $\begin{array}{l}\text { Pregnancy Induced } \\
\text { Hypertension }\end{array}$ & 57 & 52.3 \\
\hline Total & 109 & 100 \\
\hline
\end{tabular}

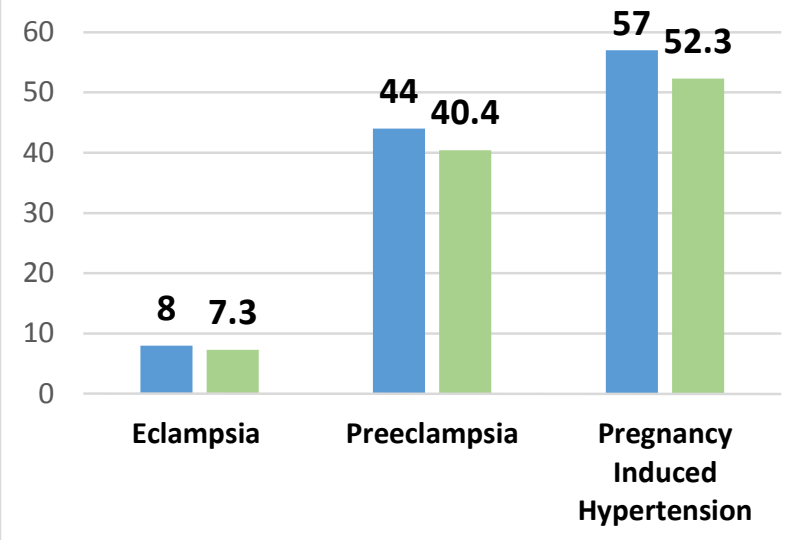

Frequency $\mathrm{n} \quad \square$ Percentage \%

Figure-2. Frequency of hypertensive disorders among 109 pregnant women

Abruption Placentae, PPH, Renal Failure, Pulmonary Edema, DIC, HELLP Syndrome, and Maternal Death were the maternal complications among 109 pregnant women while 37 had no complication as shown in Table 3.

Table-3. Prevalence of Maternal complications in 146 pregnant women
\begin{tabular}{|l|l|l|}
\hline Maternal Complications & Frequency $\mathrm{n}$ & Percentage \% \\
\hline Abruption Placentae & 7 & 6.4 \\
\hline HELLP Syndrome & 9 & 8.3 \\
\hline PPH & 5 & 4.6 \\
\hline DIC & 4 & 3.7 \\
\hline Renal Failure & 3 & 2.8 \\
\hline Pulmonary Edema & 4 & 3.7 \\
\hline Intrauterine Death & 10 & 9.2 \\
\hline No Complications & 37 & 25.34 \\
\hline
\end{tabular}

\section{DISCUSSION}

Adverse perinatal and maternal outcomes of hypertensive disorders of pregnancy are still a major challenge for the health care system, especially in developing countries. The prevalence of hypertensive disorders of pregnancy varies depending on socioeconomic status and racial differences. Other significant factors are age and parity like demographic parameters. One study reported a $1.5 \%$ to $7.5 \%$ prevalence of hypertensive disorders of pregnancy [16]. The present study found the prevalence of hypertensive disorders of pregnancy $6.2 \%$ which is slightly higher than $5.34 \%$ [17] but lower than $15 \%$ [18] reported in two different studies. Premature delivery, insufficient placental hypoxemia, and fetal growth restriction are all connected with high perinatal morbidity and mortality. On the maternal side, mortality and morbidity improved, and the frequency of cerebrovascular and cardio events, as well as long-term complications, have been reported. The majority of complications are linked to severe preeclampsia [19]. Furthermore, a previous study reported that chronic hypertension was linked to an increased risk of preeclampsia, low birth weight, preterm birth, neonatal intensive care unit admission, cesarean delivery, and perinatal mortality [20].

The disease severity is relevant to maternal complications. Conversely, prematurity and insufficient placenta are significantly associated with periodic events. Preterm delivery is caused by fetal distress and severe hypertension which leads to termination of therapeutic pregnancy. Maternal and fetal risk increases with delivery delays in uncontrolled hypertension circumstances. Intrauterine growth restriction along with preterm labor are fetal outcomes that had a significant association with hypertension in pregnancy treatment [21].

The severe complications of pregnancy-induced hypertension superimposed by preeclampsia lead to complicated 
eclampsia. A previous study reported the prevalence of $\mathrm{PIH}$ history, preeclampsia, and eclampsia were $21.4 \%, 1.2 \%$, and $2.4 \%$ respectively [22]. In our study, the majority of pregnant women had no previous hypertensive disorder or pregnancy history. In the present study, about $52.3 \%$ had $\mathrm{PIH}, 40.4 \%$ preeclampsia, and $7.3 \%$ suffered eclampsia. Another study reported prevalence of preeclampsia $50.2 \%$ and different incidence of gestational hypertension $12.5 \%$, and $35.7 \%$ eclampsia [23]. The prevalence of eclampsia was $9.5 \%$ reported in a study similar to our study finding [24]. Likewise, the prevalence of hypertensive disorder of pregnancy was $28.6 \%$ primigravida. Another major risk for hypertensive disorder is nulliparity as reported in previous studies $[25,26]$. Our study reported that hypertensive disorders of pregnancy, perinatal and maternal mortality are strongly associated with nulliparity.

Neonatal mortality is caused by low birth weight comes from hypertensive disorders of pregnancy perinatal complications such as intrauterine growth restriction and preterm birth in certain cases. Severe pre-eclampsia results in stillbirth cases in women. About 35 $(32.1 \%)$ were preterm deliveries in the present study. Our study results matched another study's findings regarding pregnancy hypertension [27]. The majority of women with hypertensive disorders of frequency delivered childbirth through vaginal delivery as reported by another study [28].

Besides hypertension, preeclampsia in proteinuria in cases was encountered with frequent clinical findings as reported in a previous study according to which eclampsia patients had $8 \%$ to $10 \%$ proteinuria without hypertension. Additionally, new-onset proteinuria developed preeclampsia in more than $50 \%$ of women within three weeks [29]. For both hypertension and proteinuria were introduced separately and had several different outcomes. Stroke is the major threat of hypertension associated with maternal and neonatal risk [30].

\section{CONCLUSION}

Our study found hypertension disorders as a significant medical disorder in pregnant women. However, neonatal outcomes and pregnancy outcomes were significantly smooth in more than $50 \%$ of pregnant women.

\section{REFERNCES}

1. Umesawa M, Kobashi G. Epidemiology of hypertensive disorders in pregnancy: prevalence, risk factors, predictors and prognosis. Hypertens Res. 2017;40:213-20.

2. Jayaram A, Collier $\mathrm{CH}$, Martin JN. Preterm parturition and preeclampsia: the confluence of two great gestational syndromes. Int $\mathrm{J}$ Gynaecol Obstet. 2020;150:10-16.

3. Martis R, Crowther CA, Shepherd E, Alsweiler J, Downie MR, Brown J. Treatments for women with gestational diabetes mellitus: an overview of Cochrane systematic reviews. Cochrane Database Syst Rev. 2018;8:CD012327.

4. Carracher AM, Marathe $\mathrm{PH}$, Close $\mathrm{KL}$. International diabetes federation 2017. J Diabetes. 2018;10:353-356.

5. Harmon AC, Cornelius DC, Amaral LM, Faulkner JL, Cunningham MW Jr., Wallace K, et al. The role of inflammation in the pathology of preeclampsia. Clin Sci. 2016;130:409-19.

6. Phipps E, Prasanna D, Brima W, Jim B. Preeclampsia: updates in pathogenesis, definitions, and guidelines. Clin J Am Soc Nephrol. 2016;11:1102-13.

7. Burton GJ, Redman CW, Roberts JM, Moffett A. Pre-eclampsia: pathophysiology and clinical implications. BMJ. 2019;366:I2381.

8. $\mathrm{Bi} J J$, Chen J. Investigation on therapeutic effect of insulin aspart and metformin on patients with gestational diabetes mellitus and its effect on serum Cys $\mathrm{C}$ and Hcy levels. Chin J Ration Drug Use. 2019;16:76-81.

9. Shuster DL, Shireman LM, Ma X, Shen DD, Flood Nichols SK, Ahmed MS, Clark S, Caritis S, Venkataramanan R, Haas DM, Quinney SK, Haneline LS, Tita AT, Manuck TA, Thummel KE, Brown LM, Ren Z, Brown Z, Easterling TR, Hebert MF. Pharmacodynamics of glyburide, metformin, and glyburide/metformin combination therapy in the treatment of gestational diabetes mellitus. Clin Pharmacol Ther. 2020;107:1362-1372.

10. Heimberger S, Mueller A, Ratnaparkhi R, Perdigao JL, Rana S Angiogenic factor abnormalities and risk of peripartum complications and prematurity among urban predominantly obese parturients with chronic hypertension. Pregnancy Hypertens. 2020;20:124-130.

11. ACOG Practice Bulletin No. 190 Summary: gestational diabetes mellitus. Obstet Gynecol. 2018;131:406-408.

12. Tang J, Zhu X, Li M, Huang D, Zhao Q. The impact of maternal prepregnancy impaired fasting glucose on preterm birth and large for gestational age: a large population-based cohort study. Am J Obstet Gynecol. 2020;222:265.e1-265.e19.

13. Budak MS, Kahramanoglu I, Vitale SG, Akgol S, Dilek ME, Kartal S, Caruso S, Kahveci B, Obut M, Bademkiran MH, Cianci A. Maternal abdominal subcutaneous fat thickness as a simple predictor for gestational diabetes mellitus. J Perinat Med. 2019;47:605-610

14. Mitchell PL, Nachbar R, Lachance D, St-Pierre P, Trottier J, Barbier $\mathrm{O}$, Marette A. Treatment with a novel agent combining docosahexaenoate and metformin increases protectin DX and IL-6 production in skeletal muscle and reduces insulin resistance in obese diabetic db/db mice. Diabetes Obes Metab. 2017;19:313-319

15. Abildgaard U, Heimdal K. Pathogenesis of the syndrome of hemolysis, elevated liver enzymes, and low platelet count (HELLP): a review. Eur J Obstet Gynecol Reprod Biol. 2013;166: 117-23.

16. John K, Wielgosz S, Schulze-Osthoff K, Bantel H, Hass R. Increased plasma levels of CK-18 as potential cell death biomarker in patients with HELLP syndrome. Cell Death Dis. 2013;4:e886.

17. Ankumah NE, Sibai BM. Chronic hypertension in pregnancy: diagnosis, management, and outcomes. Clin Obstet Gynecol. 2017;60:206-14.

18. Ankumah NA, Cantu J, Jauk V, Biggio J, Hauth J, Andrews W, et al. Risk of adverse pregnancy outcomes in women with mild chronic hypertension before 20 weeks of gestation. Obstet Gynecol 2014;123:966-72.

19. Orbach H, Matok I, Gorodischer R, Sheiner E, Daniel S, Wiznitzer A, et al.Hypertension and antihypertensive drugs in pregnancy and perinatal outcomes. Am J Obstet Gynecol. 2013:208:301.e1-6.

20. Tooher J, Thornton C, Makris A, Ogle R, Korda A, Hennessy A. All hypertensive disorders of pregnancy increase the risk of future cardiovascular disease. Hypertension. 2017;70:798-803.

21. Shen M, Smith GN, Rodger M, White RR, Walker MC, Wen SW Comparison of risk factors and outcomes of gestational hypertension and pre-eclampsia. PLoS ONE. 2017;12:e0175914.

22. Abalos E, Cuesta C, Carroli G, Qureshi Z, Widmer M, Vogel JP, et al. Pre-eclampsia, eclampsia and adverse maternal and perinatal outcomes: a secondary analysis of the World Health Organization Multicountry Survey on Maternal and Newborn Health. BJOG. 2014;121 Supply 1:14-24. Doi: 10.1111/1471-0528.12629.

23. Bramham K, Parnell B, Nelson-Piercy C, Seed PT, Poston L, Chappell LC. Chronic hypertension and pregnancy outcomes: systematic review and meta-analysis. BMJ. 2014; 348:g2301. Doi: 10.1136/bmj.g2301.

24. Bateman BT, Huybrechts KF, Fischer MA, Seely EW, Ecker JL, Oberg AS, Franklin JM, Mogun H, HernandezDiaz S. Chronic hypertension in pregnancy and the risk of congenital malformations: a cohort study. Am J Obstet Gynecol. 2015;212(3):337.e1-14. Doi: 10.1016/j.ajog. 2014.09.031.

25. Jayaram $\mathrm{A}$, Collier $\mathrm{CH}$, Martin JN. Preterm parturition and preeclampsia: the confluence of two great gestational syndromes. Int $\mathrm{J}$ Gynaecol Obstet. 2020;150:10-16

26. Martis R, Crowther CA, Shepherd E, Alsweiler J, Downie MR, Brown J. Treatments for women with gestational diabetes mellitus: an overview of Cochrane systematic reviews. Cochrane Database Syst Rev. 2018;8:CD012327.

27. Lowe SA, Bowyer L, Lust K, McMahon LP, Morton MR, North RA, et al. The SOMANZ Guidelines for the Management of Hypertensive Disorders of Pregnancy 2014. Aust N Z J Obstet Gynaecol. 2015;55(1):11-6. Doi: 10.1111/ajo.12253.

28. Tranquilli AL, Dekker G, Magee L, Roberts J, Sibai BM, Steyn W, et al. The classification, diagnosis and management of the hypertensive disorders of pregnancy: A revised statement from the ISSHP. Pregnancy Hypertens. 2014;4(2):97-104. Doi: 10.1016/j.preghy.2014.02.001.

29. Magee LA, Singer J, von Dadelszen P; CHIPS Study Group. Lesstight versus tight control of hypertension in pregnancy. N Engl J Med. 2015;372(24):2367-8. Doi: 10.1056/NEJMc1503870.

30. Farrar D, Simmonds M, Griffin S, Duarte A, Lawlor DA, Sculpher M, Fairley L, Golder S, Tuffnell D, Bland M, Dunne F, Whitelaw D, Wright $J$, Sheldon TA. The identification and treatment of women with hyperglycaemia in pregnancy: an analysis of individual participant data, systematic reviews, meta-analyses and an economic evaluation. Health Technol Assess. 2016;20:1-348. 